\title{
Efficacy and tolerability of ketogenic diet therapy in 55 Chinese children with drug-resistant epilepsy in Northwest China
}

\author{
Xiangjun Dou, Zhijing Wang, Xia Li, Yan Wang, Shanshan Jia, Xixiao Song and Dong Wang*
}

\begin{abstract}
Background: Due to the tradition of carbohydrate-rich diet, challenges exist for ketogenic diet (KD) implementation in Northwest China. This study was aimed to investigate the efficacy and tolerability of KD therapy administered with gradual initiation protocols in Chinese children with pharmacoresistant epilepsy in Northwest China.
\end{abstract}

Methods: In this single-center study, 55 children with drug-resistant epilepsy were enrolled from June 2013 to June 2019. The efficacy of KD, reasons for discontinuation, duration of retention and rate of adverse events were evaluated.

Results: Fifty-five children aged from 2.2 months to 169.7 months were included, with a median age at KD initiation of 14.1 months, and 32 cases (58.2\%) responded to the diet therapy at the last contact. The responder rates were $16.4 \%$ (9/55), 36.4\% (20/55), 30.9\% (17/55), 27.3\% (15/55) at 1, 3, 6 and 12 months, respectively. Univariate analysis indicated that the duration of epilepsy and the duration of KD therapy were predictors for KD effectiveness. Poor compliance and lack of response were main reasons for discontinuation of KD. There are a few side effects of KD, most of which were minor.

Conclusions: The KD therapy with a gradual-initiation protocol is effective and tolerable for children with drug-resistant epilepsy in Northwest China. Early start of KD and KD duration of more than 6 months may be predictive factors for KD efficacy.

Keywords: Ketogenic diet, Children, Pharmacoresistant epilepsy, Seizure

\section{Background}

Ketogenic diet (KD) consisting of high fat and low carbohydrates is an effective dietary therapy for infants and children with drug-resistant epilepsy [1, 2]. It can stimulate the liver to generate large quantities of ketone bodies. The ketone bodies have seizure-inhibitory properties, after they cross the blood-brain barrier $[2,3]$. The majority of previous studies have reported responder rates of more than $50 \%$ in patients treated with KD [4-8]. The KD therapy has a few side effects, including vomiting,

*Correspondence: douxiangjun@126.com; WDhope20@163.com Department of Pediatric neurology, Xi'an Children'Hospital, No. 69,

Xijuyuan Lane, Lianhu District, Xi'an 710003, China constipation, diarrhea, abdominal pain, hypoglycemia, hyperuricemia, hypocalcemia, acidosis, hypomagnesemia, hypercholesterolemia, micronutrient deficiencies and kidney stones [1, 4, 6-10].

In Northwest China, people have traditional diets containing high levels of carbohydrates such as wheat flour and rice. Therefore, it is difficult to introduce KD in pediatric patients in Northwest China. KD initiation generally involves a period of fasting varying from $12 \mathrm{~h}$ to $72 \mathrm{~h}$, which poses a great challenge for dietary substitution. Compared to the fasting-initiation protocol, another approach that starts from full calories and progresses with KD ratio increasing gradually from 1:1, 2:1, 3:1 to 4:1 provides the same efficiency at 3 months, with lower frequencies of weight loss, hypoglycemia, and acidosis [11]. 
Therefore, KD with the gradual-initiation protocol may be more appropriate for children in Northwest China.

Currently, few studies have reported on the KD therapy in Northwest China. In this study, we set out to assess the efficacy, tolerability and safety of KD treatment in children with drug-resistant epilepsy in Northwest China.

\section{Methods}

Fifty-five children aged from 2.2 months to 169.7 months who were diagnosed with refractory epilepsy in Northwest China were enrolled in this study, including 10 patients with structural etiology that we already reported in another study [12]. These patients started to receive the KD therapy in Xi'an Children's Hospital from June 2013 to June 2019. Clinical data were extracted with approval from the ethics committee of Xi'an Children's Hospital. The patients who had failure to respond to at least two tolerated, appropriately chosen and adequately used anti-epileptic drugs (AEDs) were included, according to the International League against Epilepsy (ILAE) definition. The exclusion criteria were having suspected or known metabolism disorder (fatty acid oxidation deficiency, ketolysis deficiency, pyruvate carboxylase deficiency, primary carnitine deficiency, porphyrinopathy, etc.), or systemic conditions (liver disease, severe heart disease, recurrent respiratory infections, hyperlipidemia, chronic diarrhea, etc.). All patients underwent baseline laboratory tests including complete blood count, $\mathrm{C}$ reactive protein analysis, electrolytes test, liver and renal function tests, ammonia and lactate test, lipid profile, blood glucose test, blood metabolism screening and urine metabolism screening. Electroencephalogramy (EEG), electrocardiogramy, and renal ultrasound were aslo performed before the KD therapy.

The KD was initiated under inpatient care without prior fasting for all the 55 patients, after the guardians gave their written informed consent, and the dietary ratio of fat to combined carbohydrate and protein increased gradually from $1: 1,2: 1,3: 1$, to $4: 1$. All of them were admitted and underwent nutritional assessments. In general, the energy intake ranged $60-80 \mathrm{kcal} / \mathrm{kg}$ per day and protein intake ranged $1-1.5 \mathrm{~g} / \mathrm{kg}$ per day. The patients also received daily supplementation of potassium citrate, multiple vitamins and trace elements. For patients taking liquid medications containing different amounts of carbohydrate, we modified medications by calculating their carbohydrate content. During the first 3 days after KD initiation, blood glucose was monitored 6 times a day and urine ketones were monitored 8 times a day. The patients' parents received extensive training including how to prepare the menus at home, how to keep a seizure diary, and possible side effects. The patients were observed for 3-5 days for side effects and tolerability, then they were discharged. After discharge, we evaluated the effect of a particular ratio of diet for 7-10 days, and then increased the dietary ratio gradually by $0.3: 1-0.5: 1$ once if necessary. During the maintenance phase, the dietary ratio was maintained at 3:1-4:1 to maximize the benefit of the diet, with modifications as needed to maintain blood ketosis and avoid hypoglycemia or acidosis.

The patients maintained AED medication during KD therapy, and the treating physician modified the AED therapy according to the clinical response, 3 months after the initiation of KD. The demographic and clinical profiles, diagnosis, etiology, seizure type, electroclinical syndrome, age of seizure onset, age of KD initiation, duration of epilepsy before KD initiation, and the usage of AEDs were recorded before KD initiation and at each follow-up visit.

In the initial weeks, blood glucose and urine ketones were monitored twice daily at home for all the patients. Urine ketones were monitored once a day and blood glucose was monitored once a week after 1 month of the KD treatment. All patients had regular follow-ups with clinical and laboratory evaluations monthly for the first 6 months, and every 3 months thereafter. The seizure frequency, adverse events and reasons for stopping the diet were recorded by the patients on seizure diary between clinic visits.

All families could contact the dietitian by telephone throughout the entire phase of KD. Seizure frequency reduction was used to evaluate the efficacy of $\mathrm{KD}$ according to a previous study [13]. Seizure reduction was classified into 5 categories: complete freedom from seizures (level 5); reduction by $90-99 \%$ (level 4 ); reduction by $50-90 \%$ (level 3); reduction by less than 50\% (level 2) and no seizure reduction (level 1). Patients who had a seizure frequency reduction of higher than $50 \%$ were defined as responders. Reasons for discontinuation, adverse events and KD duration were used to assess the tolerability of KD.

Frequency and percentages were used to describe the categorical variables. Continuous variables are presented as mean \pm standard or median [25-75 percentiles]. Factors related to the KD efficacy were analyzed by Pearson's chi-square test or Mann-Whitney $U$ test. $P<0.05$ (twosided) were considered to be statistically significant.

\section{Results}

\section{Baseline characteristics of the patients}

Sixty patients were eligible at the baseline training, 5 of them dropped out before the initiation of the study because their parents considered KD too restrictive, and 55 children (40 males and 15 females) completed the initiation process of KD. The mean age of seizure onset was 14.6 months (median 6.0 months [3.5-10.0]). The 
mean age at initiation of KD was 28.97 months (median 14.1 months [9.5-44.0]). The mean duration from seizure onset to KD initiation was 14.4 months (median 8.1 months [4.1-20.0]). Forty-five (81.8\%) children reported development delay at baseline. Thirty (54.5\%) children showed more than one seizure type, 40 (72.7\%) children were on more than 2 AEDs at the time of KD initiation, and 38 (69.1\%) children had a baseline seizure frequency of more than 5 times/day. There were 15 patients with perinatal brain injury, 8 patients with malformations of cortical development, 3 patients with the sequelae of viral encephalitis, 12 patients with genetic etiology, and 17 patients with unknown reasons (most of the parents refused to do the gene test or lumbar puncture). Characteristic information of the patients at baseline are given in Table 1.

\section{Follow-up characteristics of the patients}

The KD ratio was kept at 3:1 for most of the patients $(n=47)$, and at $4: 1$ for the remaining eight patients. All the 55 patients were on oral feeds at KD initiation, but 4 patients were changed to nasogastric feeds due to aspiration pneumonia. For children younger than 12 months, formula feeds (Keto, Ginone Medical Technology Company, Guangzhou, China) were started and breast feeding was gradually stopped. For children older than 12 months, the recipe could be completely changed to Chinese food catering which was provided by the dietitian, if the ketone body index reached a high level of steady state (urine ketone body $>3+$ ). In the recipe of Chinese food catering, Long chain triglycerides mainly consisted of ordinary meat and jade rice oil, and Medium chain triglycerides (MCT) was mainly provided by MCT oil. The mean duration of KD retention was 12.6 months (median 9.8 months [5.4-15.8], range 1.7-45.4 months).

\section{Effects on seizures}

Figure 1 depicts different seizure outcomes of the patients. The patients who achieved seizure reduction of more than $50 \%$ continued $\mathrm{KD}$ for longer periods. The retention rates were $100 \%$ (55/55), 92.7\% (51/55), $70.9 \%(39 / 55)$ and $43.6 \%(24 / 55)$ respectively at 1 month, 3 months, 6 months and 12 months. The responder proportions were $16.4 \%$ (9/55), 36.4\% (20/55), 30.9\% (17/55) and $27.3 \%(15 / 55)$ respectively at $1,3,6$ and 12 months, respectively. Thirty-two cases $(58.2 \%)$ responded to $\mathrm{KD}$

Table 1 Baseline characteristics of the patients at the time of KD initiation

\begin{tabular}{|c|c|}
\hline Baseline characteristics & Patients at the time of KD initiation \\
\hline $\begin{array}{l}\text { Age at epilepsy onset (months) } \\
\text { Age at KD initiation (months) } \\
\text { Duration of seizure onset to KD initiation (months) } \\
\text { Number of AEDs failed before the initiation of KD }\end{array}$ & $\begin{array}{l}\text { Mean:14.6, median: } 6.0[3.5-10.0] \\
\text { Mean:28.97, median:14.1 [9.5-44.0] } \\
\text { Mean:14.4, median:8.1 [4.1-20.0] } \\
\text { Mean:4.8 } \pm 1.8\end{array}$ \\
\hline $\begin{array}{l}\text { Male/female }(n) \\
\text { Global developmental delay }(n, \%)\end{array}$ & $\begin{array}{l}2.67: 1(40 / 15) \\
45,81.8 \%\end{array}$ \\
\hline \multicolumn{2}{|l|}{ Number of AED $(n, \%)$} \\
\hline$\leq 2$ & $15,27.3 \%$ \\
\hline$>2$ & $40,72.7 \%$ \\
\hline \multicolumn{2}{|l|}{ Number of seizure types $(n, \%)$} \\
\hline 1 & $25,45.5 \%$ \\
\hline$\geq 2$ & $30,54.5 \%$ \\
\hline \multicolumn{2}{|l|}{ Seizure frequency $(n, \%)$} \\
\hline$\leq 5 /$ day & $17,30.9 \%$ \\
\hline$>5 /$ day & $38,69.1 \%$ \\
\hline \multicolumn{2}{|l|}{ Etiology } \\
\hline Genetic $(n, \%)$ & $12,21.8 \%$ \\
\hline Structural $(n, \%)$ & $26,47.3 \%$ \\
\hline Unknown $(n, \%)$ & $17,30.9 \%$ \\
\hline \multicolumn{2}{|l|}{ Electroclinical syndromes $(41,74.5 \%)$} \\
\hline West syndrome $(n, \%)$ & $32,58.2 \%$ \\
\hline Dravet syndrome $(n, \%)$ & $3,5.5 \%$ \\
\hline Lennox-Gastaut syndrome $(n, \%)$ & $2,3.6 \%$ \\
\hline Ohtahara syndrome $(n, \%)$ & $2,3.6 \%$ \\
\hline Doose syndrome $(n, \%)$ & $1,1.8 \%$ \\
\hline Early myoclonic encephalopathy in infants $(n, \%)$ & $1,1.8 \%$ \\
\hline
\end{tabular}




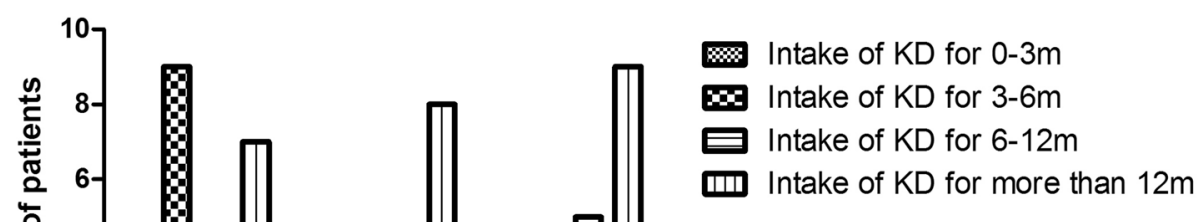

Table 2 Response rates of the patients during KD treatment

\begin{tabular}{lllll}
\hline $\begin{array}{l}\text { KD was continued } \\
\text { (range }-\mathbf{1 . 7} \text { months-45.4 months) }\end{array}$ & $\begin{array}{l}\text { At 1 month } \\
\boldsymbol{n}=\mathbf{5 5}\end{array}$ & $\begin{array}{l}\text { At 3 months } \\
\mathbf{n = 5 1}\end{array}$ & $\begin{array}{l}\text { At 6 months } \\
\boldsymbol{n}=\mathbf{3 9}\end{array}$ & $\begin{array}{l}\text { At 12 months } \\
\boldsymbol{n}=\mathbf{2 4}\end{array}$ \\
\hline $\begin{array}{l}\text { Seizure free } \\
(n=15,27.3 \%)\end{array}$ & $10.9 \%(6 / 55)$ & $23.5 \%(12 / 51)$ & $28.2 \%(11 / 39)$ \\
$\begin{array}{l}>90 \% \text { reduction } \\
(n=22,40.0 \%)\end{array}$ & $14.5 \%(8 / 55)$ & $31.4 \%(16 / 51)$ & $35.9 \%(14 / 39)$ & $50.0 \%(12 / 24)$ \\
$\begin{array}{l}>50 \% \text { reduction } \\
(n=32,58.2 \%)\end{array}$ & $16.4 \%(9 / 55)$ & $39.2 \%(20 / 51)$ & $43.6 \%(17 / 39)$ & $62.5 \%(15 / 24)$ \\
\hline
\end{tabular}

Table 3 Time of patient response to the KD treatment

\begin{tabular}{llll}
\hline $\begin{array}{l}\text { Duration of } \\
\text { KD retention }\end{array}$ & $\begin{array}{l}\text { Seizure-free } \\
\boldsymbol{n}=\mathbf{1 5}\end{array}$ & $\begin{array}{l}\mathbf{5 0 - 9 9 \%} \text { reduction } \\
\boldsymbol{n}=\mathbf{1 7}\end{array}$ & $\begin{array}{l}\text { Total } \\
\boldsymbol{n}=\mathbf{3 2}\end{array}$ \\
\hline$<1$ month & $18.8 \%(6 / 32)$ & $9.4 \%(3 / 32)$ & $28.1 \%(9 / 32)$ \\
$1-3$ months & $18.8 \%(6 / 32)$ & $18.8 \%(6 / 32)$ & $37.5 \%(12 / 32)$ \\
3-6 months & 0 & $6.3 \%(2 / 32)$ & $6.3 \%(2 / 32)$ \\
6-12 months & $9.4 \%(3 / 32)$ & $12.5 \%(4 / 32)$ & $21.9 \%(7 / 32)$ \\
$>12$ months & 0 & $6.3 \%(2 / 32)$ & $6.3 \%(2 / 32)$ \\
\hline
\end{tabular}

at the last contact, including 15 (27.3\%) who achieved seizure freedom during maintenance phase and remained seizure-free after the initial control in this study. The retention rates and effective rates were shown in Table 2.

Among the 32 cases who responded to the KD diet, 21 patients $(65.6 \%, 21 / 32)$ started to respond to KD within 3 months, including 12 patients $(37.5 \%, 12 / 32)$ who achieved seizure freedom. Besides, 11 patients (34.4\%,
$11 / 32$ ) started to respond to the diet 3 months later. Details of these patients are given in Table 3.

\section{Univariate analysis of factors affecting the KD response rate}

Univariate analysis revealed a significant association between the duration from seizure onset to KD initiation and seizure outcome $(P<0.05)$, and a significant association between the duration of KD and seizure outcome $(P<0.01)$. No significant association was found between seizure outcome and the other variables (Table 4).

\section{Reasons for discontinuation of KD}

In this study, 42 patients $(76.4 \%, 42 / 55)$ stopped the diet till the last follow-up. Among them, 19 patients $(34.5 \%, 19 / 55)$ discontinued the diet over 1 year later, 10 patients $(18.2 \%, 10 / 55)$ discontinued the diet between 6 and 12 months after initiation, 13 patients $(23.6 \%, 13 / 55)$ discontinued the diet within 6 months after initiation. Among the 23 cases who discontinued the diet within 1 year after initiation, 7 patients dropped out because of poor compliance, while 10 patients discontinued because 
Table 4 Univariate analysis of factors affecting the response rate to KD

\begin{tabular}{|c|c|c|c|c|}
\hline \multirow[t]{2}{*}{ Factor } & \multicolumn{2}{|l|}{ Outcome } & \multirow[t]{2}{*}{ Test statistic } & \multirow[t]{2}{*}{$P$ value } \\
\hline & Favorable & Unfavorable & & \\
\hline \multicolumn{5}{|l|}{ Gender } \\
\hline Male & 24 & 16 & $x^{2}=0.199$ & $P=0.655$ \\
\hline Female & 8 & 7 & & \\
\hline \multicolumn{5}{|c|}{ Age of seizure onset (months) } \\
\hline Median & $6.25[3.6-14.3]$ & $6.0[3.4-8.1]$ & $U=326.0$ & $P=0.473$ \\
\hline \multicolumn{5}{|c|}{ Age at KD initiation (months) } \\
\hline Median & $13.0[8.6-40.9]$ & $19.3[10.8-45.5]$ & $U=291.5$ & $P=0.192$ \\
\hline \multicolumn{5}{|c|}{ Duration of seizure onset to KD initiation (months) } \\
\hline \multicolumn{5}{|c|}{$\leq 6$} \\
\hline Yes & 19 & 5 & $x^{2}=7.707$ & $P=0.006^{*}$ \\
\hline No & 13 & 18 & & \\
\hline \multicolumn{5}{|l|}{$\leq 12$} \\
\hline Yes & 24 & 10 & $x^{2}=5.633$ & $P=0.018^{*}$ \\
\hline No & 8 & 13 & & \\
\hline \multicolumn{5}{|c|}{ Duration of KD retention (months) } \\
\hline$\leq 6$ & 6 & 12 & $x^{2}=6.79$ & $P=0.009^{*}$ \\
\hline$>6$ & 26 & 11 & & \\
\hline \multicolumn{5}{|c|}{ Number of AEDs at KD initiation } \\
\hline$\leq 2$ & 10 & 5 & $x^{2}=0.610$ & $P=0.435$ \\
\hline$>2$ & 22 & 18 & & \\
\hline \multicolumn{5}{|c|}{ Number of seizure types } \\
\hline 1 & 13 & 12 & $x^{2}=0.720$ & $P=0.396$ \\
\hline$\geq 2$ & 19 & 11 & & \\
\hline \multicolumn{5}{|c|}{ West syndrome } \\
\hline Yes & 19 & 1 & $x^{2}=0.045$ & $P=0.832$ \\
\hline No & 13 & 10 & & \\
\hline
\end{tabular}

Univariate analysis Chi-Square test $\left(x^{2}\right)$, Mann-Whitney $U$ test, ${ }^{*}$ level of significance $p<0.05$

of the poor effect. Reasons for discontinuation over 1 year later were: lack of efficacy in 7 patients, poor compliance in 5 patients, transition to normal diet in 5 patients, severe infection in 1 patient, and death in 1 patient. The detailed reasons for discontinuation are shown in Table 5 .

\section{Side effects of KD}

During the initiation phase of KD treatment, 4 patients had minor events including hypoglycemia (1), vomiting (2), and refusal to eat (1). During the maintenance phase of KD treatment, 14 patients had side effects including diarrhea (4), refusal to eat (3), constipation (2), hyperlipidemia (3) and aspiration pneumonia (2). Most of the side effects were minor and could be managed by adjusting the diet appropriately. Only 4 children (7.3\%) discontinued the diet during the maintenance phase because of the major adverse events like severe refusal to eat (2), recurrent aspiration pneumonia (1), and severe diarrhoea (1).

\section{Discussion}

In this study, we evaluated the effect and tolerability of $\mathrm{KD}$ which began with full calories with gradual increases of $\mathrm{KD}$ ratio, in 55 children with drug-resistant epilepsy in Northwest China. We found that $58.2 \%$ of the patients achieved seizure reduction of over $50 \%$, while $27.3 \%$ of the patients became seizure-free on KD at the last contact. This is consistent with the studies of Baby et al. which reported a responder rate of $59.4 \%$ on KD in children in South India [6], and of Lambrechts et al. that reported $50 \%$ in a randomized clinical trial (RCT) in the Netherlands [14]. A systemic review on 11 studies has reported seizure freedom in $16 \%$ of children, and a greater than $50 \%$ reduction in $56 \%$ of children [15]. Another RCT from the United Kingdom reported that $38 \%$ participants had seizure reduction of more than $50 \%$ at 3 months [16]. A chinese prospective multicenter study reported that $37.4,26.1$, and $20.4 \%$ of participants responded to the diet at 3,6 and 12 months after the initiation, including 21.7, 10.7 and $11.0 \%$ who achieved complete cessation of seizures [17]. The results of our study are comparable to previously published studies, with responder rates of $36.4 \%$ (20/55), 30.9\% (17/55) and $27.3 \%(15 / 55)$ at 3,6 and 12 months, respectively.

A single-center study [8] enrolling 389 patients in Turkey reported a retention rate of 69 and $64 \%$ at 6 and 12 months, respectively, while a Chinese prospective multicenter study [17] reported a lower retention rate of

Table 5 Time and reasons for discontinuing the KD

\begin{tabular}{|c|c|c|c|c|c|c|c|}
\hline \multirow[t]{2}{*}{ Time } & \multirow{2}{*}{$\begin{array}{l}\text { Number of } \\
\text { Cases }\end{array}$} & \multicolumn{6}{|l|}{ Reasons } \\
\hline & & $\begin{array}{l}\text { Ineffectiveness } \\
(n)\end{array}$ & $\begin{array}{l}\text { Side effects } \\
\text { (n) }\end{array}$ & $\begin{array}{l}\text { Death } \\
(n)\end{array}$ & $\begin{array}{l}\text { Severe } \\
\text { infection } \\
(n)\end{array}$ & $\begin{array}{l}\text { Lack of } \\
\text { compliance } \\
\text { (n) }\end{array}$ & $\begin{array}{l}\text { Transition to } \\
\text { normal diet } \\
\text { (n) }\end{array}$ \\
\hline$\leq 3$ months & 3 & 1 & 1 & 0 & 0 & 1 & 0 \\
\hline $3-6$ months & 10 & 5 & 1 & 0 & 1 & 3 & 0 \\
\hline $6-12$ months & 10 & 4 & 2 & 0 & 1 & 3 & 0 \\
\hline$>12$ months & 19 & 7 & 0 & 1 & 1 & 5 & 5 \\
\hline Total & 42 & 17 & 4 & 1 & 3 & 12 & 5 \\
\hline
\end{tabular}


44.8 and $26.4 \%$ at 6 and 12 months, respectively. Here, we reported retention rate of 70.9 and $43.6 \%$ at 6 and 12 months, respectively, which was similar to previous reports $[6,7]$.

According to the ILAE's updated recommendation, KD therapies should be offered to patients who had failed to respond to an average of 2.6 (standard deviation 0.9 ) AEDs [18]. However, the specific time of KD initiation has not been recommended. In the present study, a significant association was found between the duration of epilepsy and the efficacy of the diet, which is inconsistent with a previous study of Chinese children in 2013 [13]. The discrepancy may be due to the difference in the defined time limits of epilepsy duration (6 months or 1 year in our study versus 5 years in that study) [13]. Another reason may be that the KD therapy is most effective in children who have experienced seizures for shortest period of time according to previous literature [19]. Therefore, early and successful introduction of KD therapy may be an important factor for the efficacy of KD.

In our study, we also found that the continuation of the diet for $>6$ months was associated with the seizure outcome, which consistent with the previous Indian study [6]. We also found that $71.9 \%$ (23 cases) of the responders started to respond to the KD within 6 months; however, 7 cases $(21.9 \%)$ became responders between 6 months and 1 year. Similarly, a study in Turkey reported that 26 cases (8.2\%) who did not respond to KD at 3 months became responders at 12 months [8]. This may be because that children on a traditional carbohydrate-rich diet might need more time to adapt to KD and maintain a stable blood ketone level. The most important factor that affects the continuation of KD is parental effort and patience. In this study, lack of compliance and ineffectiveness of the diet were major reasons for the discontinuation of $K D$, which was similar to other studies $[6,10,13,14]$. A lot of parents discontinued the diet earlier, because the efficacy did not reach their expectation and the restrictions of the diet were difficult to adhere to.

The diet imposes strict restriction on content of carbohydrate, which conflicts with the carbohydrate-based diet in Northwest China, resulting in poor acceptability and maintenance. By gradually increasing the diet ratio, all of the 55 patients completed the initiation stage without any severe side effects. In the study of Baby et al., KD was initiated following a fasting protocol, 4 children did not complete the initiation process due to intolerance or side effects [6]. In addition, the responder rate of our study was $58.2 \%$ at the last follow-up, which was comparable to the study of Baby et al. [6]. These results indicated that the gradual initiation protocols might be advantageous in improving the patients' compliance and tolerance during the initiation phase and providing the same efficacy during the maintenance phase.

Similar to previous studies $[6,7,13-15]$, there was no significant association of age, sex, number of seizure types, number of AEDs at the initiation of KD, or epilepsy syndrome with seizure outcome in our study.

In the present study, the diet appeared to be safe, tolerable, albeit with a few adverse events. Similar to previous reports [7, 13, 16, 17, 20], 3 patients (5.5\%) experienced vomiting and slight refusal to eat during KD initiation. Without prior fasting, 1 patient $(1.8 \%)$ who was younger than 1 year developed hypoglycemia, a much lower rate than that in patients with prior fasting before initiating the diet [11]. During the maintenance phase of KD, gastrointestinal disorders such as vomiting, diarrhea, refusal to eat and constipation occurred in 14 patients $(25.5 \%)$, most of these symptoms could be easily corrected by adjusting the fatty ratio and changing the consistency of meals. The updated recommendations of ILAE report that gastrointestinal dysfunction may occur in a higher rate in up to $50 \%$ of patients [21-23]. One patient died during the diet therapy, but no KD-related side-effects were reported during the therapy before the patient's death, which we already reported in another study [12].

There were some limitations in our study. First, as the numbers in each category were too small to make any meaningful comparison, we did not analyze the seizure outcome based on different etiologies or epileptic syndromes. Second, we did not evaluate the effect of KD on EEG and cognitive development. Third, the results of the present study might be affected by the retrospective nature of data extraction.

\section{Conclusions}

Our study shows that the ketogenic diet with gradual initiation protocols is a safe, effective and tolerable treatment for children with refractory epilepsy in Northwest China. The diet should be considered earlier if the children did not respond to two appropriate AEDs. Successful introduction and regular follow-ups may improve the parental compliance, which is beneficial in seizure control. However, large-sample and multicentric prospective studies are needed to evaluate the efficacy and tolerability of different types of diets, which may be definitely helpful for patients with drug-resistant childhood epilepsies.

\section{Abbreviations}

AED: Antiepileptic drug; KD: Ketogenic diet; ILAE: International League against Epilepsy; EEG: Electroencephalogram; MCT: Medium chain triglycerides.

\section{Acknowledgements}

The authors thank all the participants who contributed to this study. 


\section{Authors' contributions}

Xiangjun Dou wrote the first draft of the manuscript. Zhijing Wang and Xia Li performed data analysis. Yan Wang, Shanshan Jia and Xixiao Song were responsible for data collection. Dong Wang initially designed and supervised the study. All authors read and approved the final manuscript.

\section{Funding}

This work was supported by the Shanxi Science and Technology Support Program (Grant number 2017SF-292).

\section{Availability of data and materials}

All the authors agreed to provide the supporting data if it is necessary.

\section{Declarations}

\section{Ethical approval and consent to participate}

This study was approved by the Institutional Ethics Committee of Xi'an Children's Hospital (registration number 20210058). Informed consent was obtained from all guardians of the participants involved in the study.

\section{Consent for publication}

All authors and the guardians of patients agreed for the publication of this study.

\section{Competing interests}

All authors declare no conflict of interest.

Received: 14 June 2021 Accepted: 16 December 2021 Published online: 03 March 2022

\section{References}

1. Kossoff EH, Zupec-Kania BA, Amark PE, Ballaban-Gil KR, Christina Bergqvist AG, Blackford R, et al. Optimal clinical management of children receiving the ketogenic diet: recommendations of the international Ketogenic diet study group. Epilepsia. 2009;50:304-17. https://doi.org/10. 1111/j.1528-1167.2008.01765.x.

2. Freeman JM, Kossoff EH, Hartman AL. The ketogenic diet: One decade later. Pediatrics. 2007;119:535-43. https://doi.org/10.1542/peds.2006-2447.

3. Papandreou D, Pavlou E, Kalimeri E, Mavromichalis I. The ketogenic diet in children with epilepsy. Br J Nutr. 2006;95:5-13. https://doi.org/10.1079/ bjn20051591.

4. Rubenstein JE, Kossoff EH, Pyzik PL, Vining EPG, McGrogan JR, Freeman JM. Experience in the use of the ketogenic diet as early therapy. J Child Neurol. 2005;20:31-4. https://doi.org/10.1177/08830738050200010501.

5. Sharma S, Gulati S, Kalra V, Agarwala A, Kabra M. Seizure control and biochemical profile on the ketogenic diet in young children with refractory epilepsy-Indian experience. Seizure. 2009;18:446-9. https://doi.org/10. 1016/j.seizure.2009.04.001.

6. Baby N, Vinayan KP, Pavithran N, Grace RA. A pragmatic study on efficacy, tolerability and long term acceptance of ketogenic diet therapy in 74 south Indian children with pharmacoresistant epilepsy. Seizure. 2018;58:41-6. https://doi.org/10.1016/j.seizure.2018.03.020.

7. Hallböök T, Sjölander A, Åmark P, Miranda M, Bjurulf B, Dahlin M. Effectiveness of the ketogenic diet used to treat resistant childhood epilepsy in Scandinavia. Eur J Paediatr Neurol. 2015;19:29-36. https://doi.org/10. 1016/j.ejpn.2014.09.005.

8. Guzel O, Uysal U, Arslan N. Efficacy and tolerability of olive oil-based ketogenic diet in children with drug-resistant epilepsy: a single center experience from Turkey. Eur J Paediatr Neurol. 2019;23:143-51. https:// doi.org/10.1016/j.ejpn.2018.11.007.

9. Nordli DR, Kuroda MM, Carroll J, Koenigsberger DY, Hirsch LJ, Bruner $\mathrm{HJ}$, et al. Experience with the ketogenic diet in infants. Pediatrics. 2001;108:129-33. https://doi.org/10.1542/peds.108.1.129.

10. Zamani GR, Mohammadi M, Ashrafi MR, Karimi P, Mahmoudi M, Badv RS, et al. The effects of classic ketogenic diet on serum lipid profile in children with refractory seizures. Acta Neurol Belg. 2016;1 16:529-34. https:// doi.org/10.1007/s13760-016-0601-x.
11. Bergqvist AGC, Schall Jl, Gallagher PR, Cnaan A, Stallings VA. Fasting versus gradual initiation of the ketogenic diet: a prospective, randomized clinical trial of efficacy. Epilepsia. 2005;46:1810-9. https://doi.org/10. 1111/j.1528-1167.2005.00282.x.

12. Xiangjun $D, X u X$, Tingting $M$, et al. Evaluation of the seizure control and the tolerability of ketogenic diet in Chinese children with structural drugresistant epilepsy. Seizure. 2021;94:43-51. https://doi.org/10.1016/j.seizu re.2021.11.008.

13. Suo C, Liao J, Lu X, Fang K, Hu Y, Chen L, et al. Efficacy and safety of the ketogenic diet in Chinese children. Seizure. 2013;22:174-8. https://doi. org/10.1016/j.seizure.2012.11.014.

14. Lambrechts DAJE, de Kinderen RJA, Vles JSH, de Louw AJA, Aldenkamp AP, Majoie HJM. A randomized controlled trial of the ketogenic diet in refractory childhood epilepsy. Acta Neurol Scand. 2017;135:231-9. https://doi.org/10.1111/ane.12592.

15. Lefevre F, Aronson N. Ketogenic diet for the treatment of refractory epilepsy in children: a systematic review of efficacy. Pediatrics. 2000;105.

16. Neal EG, Chaffe H, Schwartz RH, Lawson MS, Edwards N, Fitzsimmons $\mathrm{G}$, et al. The ketogenic diet for the treatment of childhood epilepsy: a randomised controlled trial. Lancet Neurol. 2008;7:500-6. https://doi.org/ 10.1016/S1474-4422(08)70092-9.

17. Qin S, Qin Q, Zhou S, et al. Rospective multicenter study on long term ketogenic diet therapy for intractable childhood epilepsy. Chin J Pediatr. 2013;51(4):276-82 10.3760cma.j.issn.0578.1310.2013.04.008.

18. Kossoff EH, Zupec-Kania BA, Auvin S, Ballaban-Gil KR, Christina Bergqvist $A G$, Blackford R, et al. Optimal clinical management of children receiving dietary therapies for epilepsy: updated recommendations of the international Ketogenic diet study group. Epilepsia Open. 2018;3:175-92. https:// doi.org/10.1002/epi4.12225

19. Henderson CB, Filloux FM, Alder SC, Lyon JL, Caplin DA. Efficacy of the ketogenic diet as a treatment option for epilepsy: meta-analysis. J Child Neurol. 2006;21(March (3)):193-8. https://doi.org/10.2310/7010. 2006.00044.

20. Kossoff EH, McGrogan JR, Bluml RM, Pillas DJ, Rubenstein JE, Vining EP. A modified Atkins diet is effective for the treatment of intractable pediatric epilepsy. Epilepsia. 2006. https://doi.org/10.1111/j.1528-1167.2006.00438.x.

21. Katyal NG, Koehler AN, McGhee B, Foley CM, Crumrine PK. The ketogenic diet in refractory epilepsy: the experience of Children's Hospital of Pittsburgh. Clin Pediatr (Phila). 2000;39:153-9. https://doi.org/10.1177/00099 2280003900303.

22. Caraballo R, Vaccarezza M, Cersósimo R, Rios V, Soraru A, Arroyo H, et al. Long-term follow-up of the ketogenic diet for refractory epilepsy: multicenter Argentinean experience in 216 pediatric patients. Seizure. 2011;20:640-5. https://doi.org/10.1016/j.seizure.2011.06.009.

23. Lin A, Turner Z, Doerrer SC, Stanfield A, Kossoff EH. Complications during Ketogenic diet initiation: prevalence, treatment, and influence on seizure outcomes. Pediatr Neurol. 2017;68:35-9. https://doi.org/10.1016/j.pedia trneurol.2017.01.007.

Ready to submit your research? Choose BMC and benefit from:

- fast, convenient online submission

- thorough peer review by experienced researchers in your field

- rapid publication on acceptance

- support for research data, including large and complex data types

- gold Open Access which fosters wider collaboration and increased citations

- maximum visibility for your research: over 100M website views per year

At BMC, research is always in progress.

Learn more biomedcentral.com/submissions 